\title{
Neuroradiographic findings in 22q11.2 deletion syndrome
}

\author{
Lauren A. Bohm ${ }^{1,2,3}$ (iD | Tom C. Zhou ${ }^{1}$ (i) | Tyler J. Mingo ${ }^{1}$ | Sarah L. Dugan ${ }^{4,5}$ | \\ Richard J. Patterson $^{6}$ | James D. Sidman ${ }^{1,2}$ | Brianne B. Roby ${ }^{1,2}$
}

1 University of Minnesota, Minneapolis, Minnesota

2 ENT and Facial Plastic Surgery, Children's Minnesota, Children's Specialty Center, Minneapolis, Minnesota

${ }^{3}$ Division of Pediatric Otolaryngology, University of Michigan, Ann Arbor, Michigan

4 Medical Genetics, Children's Minnesota, Minneapolis, Minnesota

${ }^{5}$ Division of Pediatric Genetics, University of Utah, Salt Lake City, Utah

6 Pediatric Radiology, Children's Minnesota, Minneapolis, Minnesota

\section{Correspondence}

Dr. Brianne B. Roby, ENT and Facial Plastic Surgery, Children's Minnesota, Children's Specialty Center-Suite 450, 2530 Chicago Avenue South, Minneapolis, MN 55404. Email: barne284@umn.edu

$22 q 11.2$ deletion syndrome (22q11.2DS) is a common genetic disorder with enormous phenotypic heterogeneity. Despite the established prevalence of developmental and neuropsychiatric issues in this syndrome, its neuroanatomical correlates are not as well understood. A retrospective chart review was performed on 111 patients diagnosed with 22q11.2DS. Of the 111 patients, 24 with genetically confirmed 22q11.2 deletion and brain MRI or MRA were included in this study. The most common indications for imaging were unexplained developmental delay (6/24), seizures of unknown etiology (5/24), and unilateral weakness (3/24). More than half $(13 / 24)$ of the patients had significant radiographic findings, including persistent cavum septi pellucidi and/or cavum vergae (8/24), aberrant cortical veins (6/24), polymicrogyria or cortical dysplasia (4/24), inner ear deformities (3/24), hypoplastic internal carotid artery (2/24), and hypoplastic cerebellum (1/24). These findings reveal the types and frequencies of brain malformations in this case series, and suggest that the prevalence of neuroanatomical abnormalities in 22q11.2DS may be underestimated. Understanding indications for imaging and frequently encountered brain malformations will result in early diagnosis and intervention in an effort to optimize patient outcomes.

\section{KEYWORDS}

22q11.2 deletion syndrome, brain, developmental delay, DiGeorge syndrome, magnetic resonance imaging, velocardiofacial syndrome

\section{1 | INTRODUCTION}

22q11.2 deletion syndrome (22q11.2DS) is a common genetic disorder with an estimated incidence of 1 in 4,000 live births (Goodship, Cross, LiLing, \& Wren, 1998; Óskarsdóttir, Vujic, \& Fasth, 2004; Tezenas Du Montcel, Mendizabai, Ayme, Levy, \& Philip, 1996). It is often referred to as velocardiofacial syndrome (VCFS), and is associated with the phenotype the name suggests-palatal dysfunction, conotruncal heart defects, and characteristic facies. While these are often the most recognized findings, 22q11.2 deletion is associated with enormous

Lauren A. Bohm and Tom C. Zhou contributed equally to this work. phenotypic heterogeneity; over 180 features have been described (Robin \& Shprintzen, 2005).

Approximately $93 \%$ of $22 q 11.2$ deletions arise de novo (McDonald-McGinn \& Zackai, 2008). The remaining 7\% have an autosomal dominant inheritance pattern. A hemizygous deletion is sufficient to produce the full syndrome, but the size and extent of the deletion has not correlated well with clinical expression. The deletion site is flanked by low-copy repeats whose high homology to one another makes this region especially susceptible to rearrangement from unequal meiotic crossovers and non-allelic homologous recombination (Edelmann, Pandita, \& Morrow, 1999). Most patients (85\%) have an approximate 3-Mb deletion encompassing 45 functional genes, $8 \%$ have a $1.5-\mathrm{Mb}$ deletion, and the remainder 
have variable deletion sizes (Emanuel, 2008). Since 1992, fluorescence in situ hybridization (FISH) studies using TUPLE1 and N25 probes have allowed clinical laboratories to identify patients with the 22q11.2 deletion, which is almost always too small to be identified by conventional cytogenetic studies. The probe is limited to one single target sequence within the 22q11.2 deletion region, and atypical deletions may not include the region specific to the probe. Other more sensitive techniques include array comparative genomic hybridization $(\mathrm{aCGH})$ and single nucleotide polymorphism (SNP) array.

Management of patients with 22q11.2DS requires coordinated multidisciplinary care, and guidelines on management are available (Bassett et al., 2011; Fung et al., 2015). While many of the life-threatening features of 22q11.2DS are addressed in infancy, the potential for developmental delay, learning disabilities, behavioral impairment and psychiatric illness require continued surveillance and therapy into adulthood. 22q11.2DS is the second most common genetic cause of developmental delay and accounts for $2.4 \%$ of individuals with developmental disabilities (Rauch et al., 2006). Motor and speech-language delays are commonly observed during early childhood; while specific learning disabilities are often identified in primary school ages (Swillen \& McDonald-McGinn, 2015). The cognitive capabilities of patients with 22q11.2DS are highly variable. The majority of affected individuals demonstrate borderline intellectual levels, and $40 \%$ demonstrate mild to moderate intellectual disability (De Semdt et al., 2007).

In addition, patients with 22q11.2DS are at notably higher risk of behavioral and psychiatric manifestations, including attention deficit hyperactivity disorder, autism spectrum disorder, bipolar disorder, depression, anxiety, obsessive compulsive disorder, and schizophrenia (Kobrynski \& Sullivan, 2007). Studies suggest 9-50\% of 22q11.2DS patients develop behavioral or psychiatric problems at some point in their lifetime (Kobrynski \& Sullivan, 2007). The study of 22q11.2DS thus offers a unique opportunity to understand the neuroanatomical differences of certain mental health disorders as they relate to genetics.

Studies of patients with 22q11.2DS have demonstrated a range of neuroanatomical abnormalities. Qualitative studies have reported increased prevalence of developmental midline anomalies (e.g., abnormalities of the septi pellucidi, agenesis of the corpus callosum) (Campbell et al., 2006; Chow et al., 1999; Kraynack, Hostoffer, \& Robin, 1999; Ryan et al., 1997; Van Amelsvoort et al., 2001), polymicrogyria (Bingham, Lynch, McDonald-McGinn, \& Zackai, 1998; Cramer, Schaefer, \& Krishnamoorthy, 1996; Ghariani et al., 2002; Kawame, Kurosawa, Akatsuka, Ochiai, \& Mizuno, 2000; Robin et al., 2006), increased white matter hyperintensities (Campbell et al., 2006; Mitnick, Bello, \& Shprintzen, 1994; Van Amelsvoort et al., 2001), hippocampal malrotation (Andrade, Krings, Chow, Kiehl, \& Bassett, 2013), ventricular enlargement (Chow et al., 1999), hypoplastic cerebellar vermis and cerebellar atrophy (Bish et al., 2006; Lynch et al., 1995; Mitnick et al., 1994; Van Amelsvoort et al., 2001).
Quantitative studies using brain MRI have further noted a decrease in total brain volume by $8.5-11 \%$ (Eliez, Schmitt, White, \& Reiss, 2000; Kates et al., 2004; Simon et al., 2005) and multiple regional changes, such as increased size of caudate nucleus and insula, and decreased amygdala size (DeBoer, Wu, Lee, \& Simon, 2007; Eliez, Barnea-Goraly, Schmitt, Liu, \& Reiss, 2002; Jalbrzikowski et al., 2013). Clinically, nearly 50\% of 22q11.2DS patients have microcephaly (Barnea-Goraly, Eliez, Menon, Bammer, \& Reiss, 2005; Campbell et al., 2006). The cellular mechanisms leading to these changes have yet to be elucidated.

While there has been some progress in identifying brain malformations in patients with 22q11.DS, it is unclear how frequently brain abnormalities are present in the 22q11.2DS population. Furthermore, the implications of those brain malformations in the 22q11.2DS population as a whole remain unclear. This paper reviews patients with 22q11.2DS and brain MRI/MRA, who presented to clinic for multidisciplinary care.

\section{2 | MATERIALS AND METHODS}

This study is a retrospective chart review from a tertiary children's hospital. Institutional Review Board approval and HIPAA waiver were obtained from Children's Minnesota. Patients who presented at the VCFS Clinic from April 14, 2009 to May 1, 2014 were reviewed within the Children's Minnesota electronic medical record.

One hundred eleven consecutive patients presenting to the VCFS Clinic were identified as potential patients for the study. Of those patients, 26 had a documented brain MRI or MRA. One patient had a brain MRI performed and stored at an outside institution, and image results could not be obtained. Another patient had clinical features of 22q11.2DS, but both FISH and aCGH were negative for 22q11.2 deletion. These two patients were excluded from the study. Therefore, a total of 24 patients with brain MRI or MRA reports available and only those with confirmed 22q11.2 deletions by FISH using TUPLE1 probe or by aCGH were included.

The medical records of the 24 patients were reviewed and data was collected on developmental history, seizures, head circumference, and medical comorbidities. In the analysis, medical comorbidities were categorized using the grouping in the practical guidelines for multidisciplinary management of 22q11.2DS (Bassett et al., 2011) as a reference. Clinical judgment was utilized to categorize medical comorbidities that were not specifically addressed in the guidelines. A patient was defined as having macrocephaly or microcephaly if the head circumference at any point during development was greater than or equal to two standard deviations above ( $\geq 97.5$ percentile) or below $(\leq 2.5$ percentile) the mean, respectively.

Original imaging scans were available in 19 of the 24 patients, and a single pediatric neuroradiologist (R.J.P.) independently reviewed all these images. For the remaining five patients, the results of the imaging report as dictated by the original reading radiologist were used. All institutional imaging was obtained using a GE 1.5 Tesla MRI with a 
standard sequencing protocol, which includes sagittal T1, axial and coronal fast spin echo T2, axial FLAIR and axial diffusion-weighted images. For patients with multiple brain MRIs/MRAs, the latest imaging was used to identify brain malformations because pathology is more likely to be identified in a more developed brain (e.g., myelination). However, in these patients, the indication for obtaining the first imaging was recorded.

\section{3 | RESULTS}

This series of 24 patients was comprised of 14 males and 10 females. The age at which the last brain MRI or MRA was obtained ranged from 7 days to 8 years 6 months, with the mean age of 2 years 1 month. Of the 24 patients, 21 underwent brain MRI without contrast, two underwent brain MRA, and one underwent both brain MRI without contrast and brain MRA. In addition to the 22q11.2 deletion, three patients had additional copy number variants of unknown significance identified, including gains at $5 q 35.3$ and 9 p24.1, and loss at 15q11.2. The frequencies of medical comorbidities in these 24 patients are shown in Table 1 . The clinical features of these patients were very similar to the general 22q11.2DS population as reported in the literature. However, this patient sample had more neurological issues.

Indications for brain imaging in the 24 patients are shown in Figure 1. The most common indications were unexplained developmental delay (6 of 24), seizures of unknown etiology (5 of 24), and unilateral weakness ( 3 of 24). Two patients had imaging performed to evaluate for aberrant vasculature and unspecified congenital anomalies. Other indications occurred in one patient each and included microcephaly, dysphagia, recurrent clubfoot, vertigo, hypoxemicischemic insult, and headache.

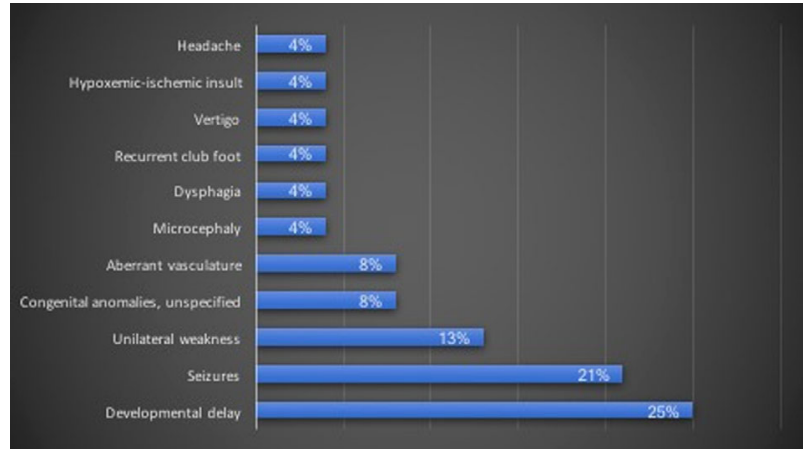

FIGURE 1 Indications for brain imaging. The top three indications for brain imaging are developmental delay, seizures, and unilateral weakness. [Color figure can be viewed at wileyonlinelibrary.com]

Nearly half of the patients had abnormal head circumferences. While 12 (50\%) of 24 patients were normocephalic, 8 (33\%) were microcephalic, and 2 (8\%) were macrocephalic (Table 2). No head circumference data were available for the remaining 2 (8\%) patients.

Interestingly, more than half of the patients with brain imaging had remarkable findings (Table 3). The most common finding was persistent cavum septi pellucidi and/or cavum vergae, seen in 8 of $24(33 \%)$ patients. Aberrant cortical veins were seen in $6(25 \%)$ patients. These veins were considered abnormal due to their size, number, or organization (Figure 2). Migrational disorders, such as polymicrogyria and cortical dysplasia, were seen in 4 (17\%) patients (Figure 3a,b). Three (13\%) patients had inner ear deformities that consisted of vestibular dysplasia (Figure 4a,b). Lastly, 2 (8\%) patients had hypoplastic internal carotid arteries (Figure 5a,b), and 1 (4\%) patient had a hypoplastic cerebellum. It is important to note that 11 (46\%) of 24 patients had no evidence of brain malformations.

TABLE 1 List of medical comorbidities and their relative frequency as compared to 22q11.2DS population

\begin{tabular}{|llll} 
List of medical comorbidities & Number, & Frequency of finding in & $\begin{array}{l}\text { Frequency of finding in 22q11.2DS population (\%) } \\
\text { (Bassett et al., 2005, 2011; Kobrynski \& Sullivan, 2007; } \\
\text { sample (\%) }\end{array}$ \\
$\begin{array}{l}\text { Developmental delay and cognitive } \\
\text { impairment }\end{array}$ & 20 & 83 & $75-90$ \\
\hline $\begin{array}{l}\text { Otolaryngologic } \\
\text { Neurological }\end{array}$ & 19 & 79 & $69-100$ \\
\hline Cardiovascular & 19 & 79 & $8-40$ \\
\hline Musculoskeletal & 16 & 67 & $49-83$ \\
\hline Immune-related & 13 & 54 & $15-59$ \\
\hline Genitourinary & 9 & 38 & $35-77$ \\
\hline Gastrointestinal & 6 & 25 & $10-37$ \\
\hline Psychiatric & 6 & 25 & $6-36$ \\
\hline Premature & 5 & 21 & $9-50$ \\
\hline Endocrine & 4 & 17 & - \\
\hline Hematologic & 4 & 17 & $17-60$ \\
\hline Ophthalmologic & 2 & 8 & $6-30$ \\
\hline
\end{tabular}


TABLE 2 Head circumference

\begin{tabular}{lll} 
& Number, $\mathbf{N = 2 4}$ & $\begin{array}{l}\text { Frequency of } \\
\text { finding in sample (\%) }\end{array}$ \\
\hline Normal & 12 & 50 \\
\hline Microcephaly & 8 & 33 \\
\hline Macrocephaly & 2 & 8 \\
\hline Data not available & 2 & 8 \\
\hline
\end{tabular}

\section{4 | DISCUSSION}

The study herein describes 24 patients with genetically confirmed 22q11.2 deletion and brain MRI or MRA. The medical comorbidities suggest that the 24 patients are a representative sample of the 22q11.2DS population. As seen in Table 1, the frequencies of medical comorbidities in this patient sample fall within the ranges cited in the literature, with the exception of neurological conditions. The discrepancy seen amongst neurologic conditions likely stems from inconsistent classification systems used in the literature. Other authors may have used different classifications, leading to a lower overall incidence of neurological findings in their cohorts of patients (Bassett et al., 2005; Ryan et al., 1997). In order to be comprehensive, this study did not limit neurologic conditions to structural abnormalities of the brain, but also included spinal cord pathology, seizures, and neurovascular abnormalities.

The other possibility is that the prevalence of neurological abnormalities is underestimated since brain MRI, unlike renal ultrasound and echocardiogram, is not routinely obtained in patients with 22q11.2DS. In this sample, approximately $23 \%$ (26 of 111) of patients with 22q11.2DS underwent brain MRI or MRA. There is no previously published data on the percentage of patients, who undergo brain imaging in this population. In comparison, renal ultrasound and echocardiogram are recommended in all patients with 22q11.2DS at the time of diagnosis (Bassett et al., 2011). This study elucidated radiographic abnormalities, such as aberrant cortical veins and vestibular dysplasia, that have not been previously identified in this population.

TABLE 3 Brain MRI findings and their frequencies

\begin{tabular}{|lll}
\hline List of brain MRI findings & Number, & $\begin{array}{l}\text { Frequency of } \\
\text { finding in sample } \\
\text { (\%) }\end{array}$ \\
\hline None & 11 & 46 \\
\hline $\begin{array}{l}\text { Persistent cavum septi pellucidi } \\
\text { and/or cavum vergae }\end{array}$ & 8 & 33 \\
\hline Aberrant cortical veins & 6 & 25 \\
\hline $\begin{array}{l}\text { Migrational disorders } \\
\text { Inner ear deformities }\end{array}$ & 4 & 17 \\
\hline $\begin{array}{l}\text { Hypoplastic internal carotid } \\
\text { artery }\end{array}$ & 3 & 13 \\
\hline Hypoplastic cerebellum & 2 & 8 \\
\hline
\end{tabular}

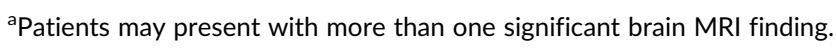

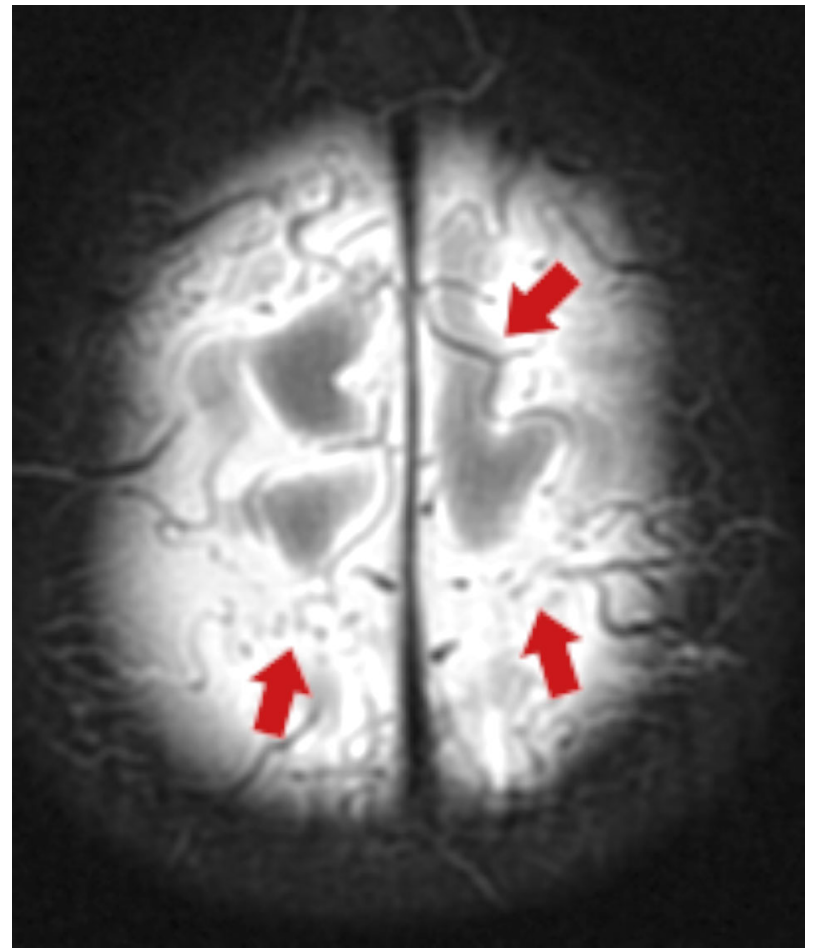

FIGURE 2 Axial T2 FSE brain MRI demonstrating numerous small caliber cortical veins (arrows) at the vertex. [Color figure can be viewed at wileyonlinelibrary.com]

A number of previous reports of neuroanatomical findings in patients with 22q11.2DS were confirmed in this study. In this review, four patients (17\%) had evidence of migrational disorders, including polymicrogyria and cortical dysplasia. Polymicrogyria, a developmental malformation of neuronal migration resulting in deranged cortical layer organization and excessive number of small gyri, was a significant finding in 3 of 24 patients (Figure 3a). Despite the rarity of polymicrogyria, it remains as one of the more common brain malformations in patients with 22q11.2DS (Bingham et al., 1998; Cramer et al., 1996; Ghariani et al., 2002; Kawame et al., 2000; Robin et al., 2006).

The pathogenesis of polymicrogyria in 22q11.2DS remains unclear, but a number of reports suggest a vascular mechanism involving hypoperfusion of the brain (Robin et al., 2006). Haploinsufficiency of TBX1, a key gene deleted in the 22q11.2 region and identified to be responsible for many of the cardiovascular phenotypes in 22q11.2DS, was recently discovered to be involved in brain angiogenesis in mice (Cioffi et al., 2014). Additionally, a range of cardiac and Circle of Willis anomalies have been described (Shprintzen, 2008). Schaer et al. (2009) report a correlation between reduced total brain volume and gyrification in 22q11.2DS patients with significant congenital cardiac disease. Of the three patients with polymicrogyria in this study, only one had cardiac defects. However, the possible association of polymicrogyria with other comorbidities is not adequately addressed here due to a small sample size.

The incidence of polymicrogyria in 22q11.2DS is estimated to be $1 \%$ (McDonald-McGinn \& Sullivan, 2011). The incidence of 


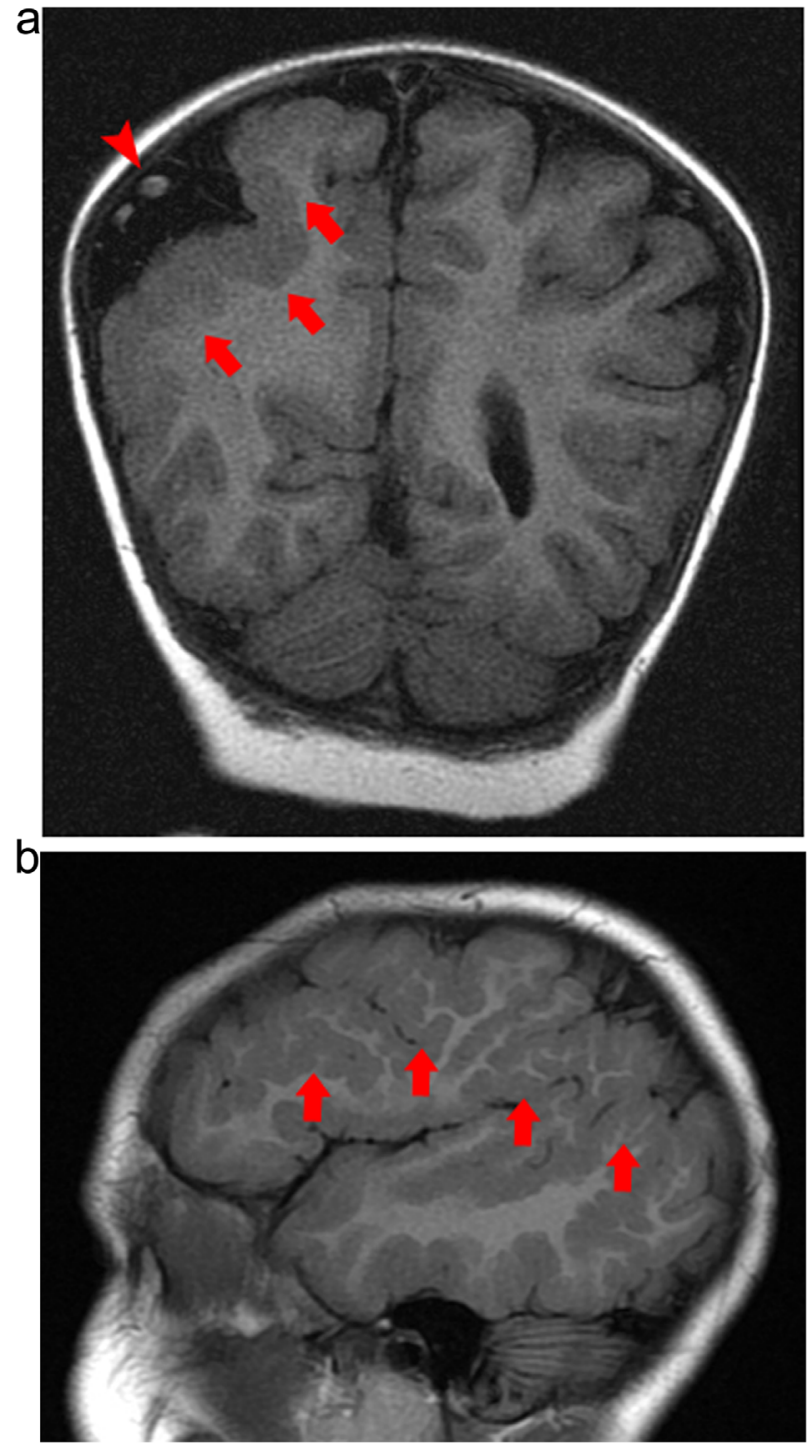

FIGURE 3 Coronal T1 Flair brain MRI demonstrating perisylvian polymicrogyria on the right (arrows) with a prominent cortical vein (arrowhead) overlying the malformation (a). Sagittal T1 brain MRI showing extensive cortical dysplasia (arrows) involving frontal and temporal lobes (b). [Color figure can be viewed at wileyonlinelibrary.com]

polymicrogyria in the general population is unknown due to clinical and radiographic heterogeneity. The clinical presentation depends on extent and severity of cortical involvement, and may vary from mild developmental delay to quadriplegia and intractable epilepsy. Likewise, radiographic imaging is variable due to the type of imaging modality, stage of maturity/myelination, and type of polymicrogyria (Barkovich, 2010). Hence, subtle polymicrogyria may be missed. Based on the positive finding in at least 3 of the 111 studied patients with 22q11.2DS, the incidence is estimated to be at least $2.7 \%$.

Cortical dysplasia, another neuronal migration abnormality, has been reported in 22q11.2DS previously (Bird \& Scambler, 2000). Sprecher et al. (2005) demonstrated that the homozygous mutation of synaptosome associated protein 29 (SNAP29), located outside the

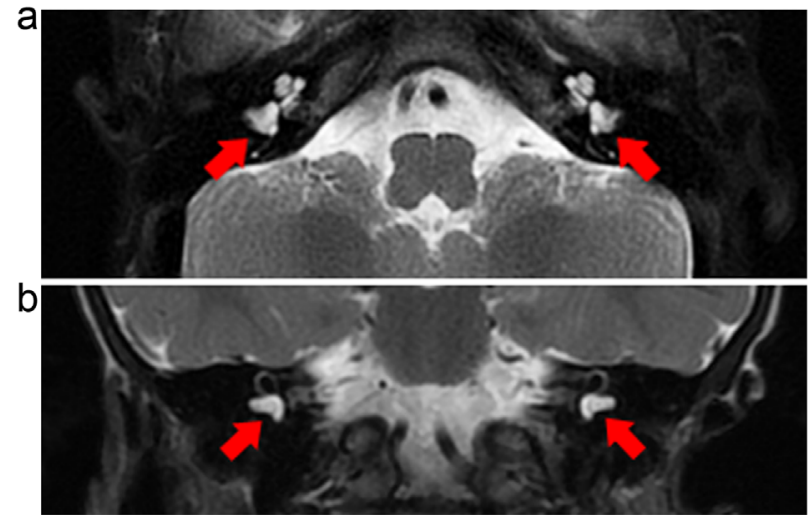

FIGURE 4 T2 FSE brain MRI showing lateral semicircular canal dysplasia (arrows) in axial (a) and coronal (b) planes in one patient. [Color figure can be viewed at wileyonlinelibrary.com]

$1.5-\mathrm{Mb}$ region but within the $3-\mathrm{Mb}$ region of the $22 \mathrm{q} 11.2$ deletion, is linked to cortical dysplasia in a rare autosomal recessive condition. Severe cortical dysplasia was seen in one patient in this review; however, aCGH demonstrated only a 1.4-Mb deletion.

This study demonstrates neurovascular findings previously unidentified in patients with 22q11.2DS. In six patients, abnormal cortical veins were seen. Two of these six patients also had migrational disorders with abnormally enlarged cortical veins superficial to the dysplastic cortex (Figure 3a). Similar findings have been reported in patients with polymicrogyria and are useful adjuncts in making a radiographic diagnosis of polymicrogyria (Hayashi, Tsutsumi, \& Barkovich, 2002). In the remaining four patients, the cortical veins, in contrast, were smaller in caliber, abnormal in number, or disorganized in appearance (Figure 2). The exact cause for this is unclear, but it is speculated this may be due to an arrest in the development and coalescence of microveins. Interestingly, three of these four patients also had prominent extra-axial spaces or enlarged ventricles. It has yet to be determined whether venous abnormalities cause insufficient drainage, in turn causing prominent extra-axial spaces or enlarged ventricles.

Additionally, arterial abnormalities were observed in some patients. Two patients had unilateral hypoplastic internal carotid
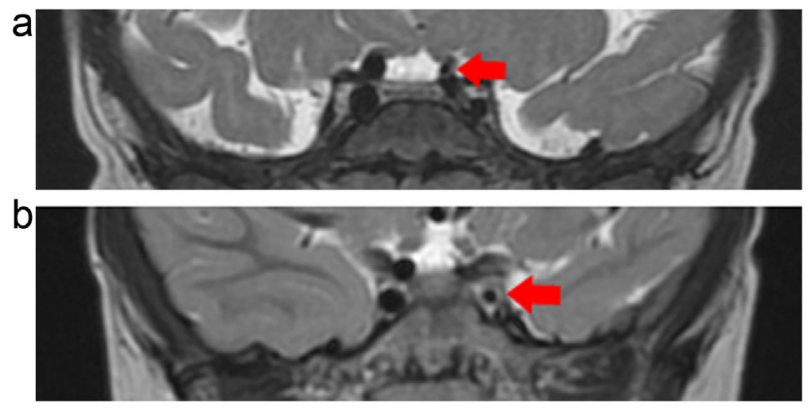

FIGURE 5 Coronal T2 FSE brain MRI illustrating hypoplastic left internal carotid artery (arrows) involving the terminus in one patient (a) and the caverous segment in another patient (b). [Color figure can be viewed at wileyonlinelibrary.com] 
arteries (ICA) at the carotid terminus or cavernous segment (Figure 5a, $\mathrm{b}$, respectively), and one of these patients also had polymicrogyria on the ipsilateral side. It is not clear whether hypoperfusion of the brain leads to polymicrogyria in these cases, but this association has been suggested, as discussed earlier. Hypoplasia of the ICA can present as cerebral ischemia or hemorrhage, and patients with this anomaly have associated variations of the Circle of Willis, increased incidence of intracranial aneurysms and extensive networks of collateral vessels to compensate for the diminished carotid flow (Osborn, Mojtahedi, Hay, \& Dewitt, 1986).

Other findings included persistent cavum septi pellucidi and/or cavum vergae, inner ear anomalies, and a hypoplastic cerebellum. In this study, cavum septi pellucidi and/or cavum vergae were defined as persistent if they were present on imaging after 6 months of age. Persistent cavum septi pellucidi and/or cavum vergae, the most common brain MRI findings in these patients, have been previously reported in individuals with 22q11.2DS (Campbell et al., 2006; Chow et al., 1999; Schmitt et al., 2014; Van Amelsvoort et al., 2001). Hypoplastic cerebellum, as seen in one patient, has also been demonstrated (Bish et al., 2006; Lynch et al., 1995; Mitnick et al., 1994; Van Amelsvoort et al., 2001). Inner ear anomalies, such as vestibular dysplasia (Figure 4a,b), were seen in three patients in this case series. The significance of these inner ear anomalies is unclear. None of these patients had sensorineural hearing loss. However, TBX1 has also been implicated in inner ear malformations in mice (Vitelli et al., 2003).

The most common indications for brain imaging in these patients together represented a majority (59\%) of the patients with 22q11.2DS and included unexplained developmental delay, seizures of unknown etiology, and unilateral weakness. All the patients who underwent imaging to evaluate for anatomical causes of developmental delays in this study did so prior to their diagnosis of 22q11.2DS. In fact, the detection of certain neuroanatomical abnormalities prompted further genetic evaluation in some cases. For example, it is recommended that FISH analysis for 22q11.2 be performed in all patients with perisylvian polymicrogyria (Guerrini \& Carrozzo, 2001). Conversely, patients with a known diagnosis of 22q11.2DS and expected developmental delays did not receive any brain imaging. Neuroimaging may be considered when the degree of developmental delay exceeds normative expectations for 22q11.2DS patients.

While seizures in 22q11.2DS are usually attributed to hypocalcemia or fever, seizures without a clear explanation may also be an indication for neuroimaging. Undiagnosed brain abnormalities such as cortical dysplasia can lower the seizure threshold in at risk patients. Obtaining MRI would allow prognostication regarding the likelihood of future seizures. Focal neurological findings manifested as unilateral weakness (e.g., hemiparesis or unilateral facial palsy) may indicate a localized brain lesion and warrant further imaging as medical or surgical intervention may be needed to address underlying brain anomalies.

Limitations to this study include its retrospective nature and risk of selection bias of the patient series. Patients with indications for brain MRI (e.g., seizures, developmental delay, microcephaly, and unilateral weakness) are more likely to have preexisting and previously undetected neurological pathology. For example, patients with polymicrogyria had a greater degree of developmental delay than is typical for 22q11.2DS (Robin et al., 2006). However, the studied patients as a group have developmental delay similar to that of the general 22q11.2DS population. Another limitation of this study is the potential for confounding bias in a few of the patients. Three patients had copy number variants of unknown significance in addition to 22q11.2 deletion. The association between these genetic mutations and the brain imaging findings is unknown.

By identifying patients with 22q11.2DS with neuroanatomical abnormalities, early diagnosis and intervention may provide the best opportunity to improve their clinical course. Patients with brain malformations may require additional early childhood special education, psychiatric evaluation and management, higher clinical suspicion for seizures, or neurosurgical interventions. Also, the cluster of radiographic findings in a patient without a prior diagnosis of 22q11.2DS, including cavum septi pellucidi and/or cavum vergae, polymicrogyria or cortical dysplasia, inner ear anomalies, aberrant cortical veins, hypoplastic internal carotid artery, and hypoplastic cerebellum, should raise suspicion for 22q11.2DS and suggest referral for a genetics evaluation.

\section{5 | CONCLUSION}

22q11.2 DS is a common genetic disorder with enormous phenotypic heterogeneity. While there has been significant progress in identifying brain malformations in patients with 22q11.DS, the implications of those brain malformations is unclear. This study reveals the types and frequencies of brain malformations, and suggests that the prevalence of neurological anomalies may be underestimated in this population. A better understanding of indications for imaging and frequently encountered brain malformations will result in early diagnosis and intervention in an effort to optimize patient outcomes.

\section{ACKNOWLEDGMENTS}

The authors would like to thank all of the participating patients in this study. In addition, authors would like to thank all the faculty and staff involved in Velocardiofacial Clinic at Children's Minnesota.

\section{DISCLOSURE}

The authors of this paper do not have any conflicts of interest to declare.

\section{REFERENCES}

Andrade, D. M., Krings, T., Chow, E. W., Kiehl, T. R., \& Bassett, A. S. (2013). Hippocampal malrotation is associated with chromosome $22 \mathrm{q} 11.2$ microdeletion. Canadian Journal of Neurological Sciences, 40(5), 652-656.

Barkovich, A. J. (2010). Current concepts of polymicrogyria. Neuroradiology, 52, 479-487. 
Barnea-Goraly, N., Eliez, S., Menon, V., Bammer, R., \& Reiss, A. L. (2005). Arithmetic ability and parietal alterations: A diffusion tensor imaging study in velocardiofacial syndrome. Brain Research. Cognitive Brain Research, 25, 735-740.

Bassett, A. S., Chow, E. W. C., Husted, J., Weksberg, R., Caluseriu, O., Webb, G. D., \& Gatzoulis, M. A. (2005). Clinical features of 78 adults with 22q11 deletion syndrome. American Journal of Medical Genetics Part A, 138A, 307-313.

Bassett, A. S., McDonald-McGinn, D. M., Devriendt, K., Digilio, M. C., Goldenberg, P., Habel, A., ... Vorstman, J. (2011). Practical guidelines for managing patients with 22q11.2 deletion syndrome. Journal of Pediatrics, 159, 332-339.

Bingham, P. M., Lynch, D., McDonald-McGinn, D., \& Zackai, E. (1998). Polymicrogyria in chromosome 22 deletion syndrome. Neurology, 51, 1500-1502.

Bird, L. M., \& Scambler, P. (2000). Cortical dysgenesis in 2 patients with chromosome 22q11 deletion. Clinical Genetics, 58, 64-68.

Bish, J. P., Pendyal, A., Ding, L., Ferrante, H., Nguyen, V., McDonaldMcGinn, D., ... Simon, T. J. (2006). Specific cerebellar reductions in children with chromosome 22q11.2 deletion syndrome. Neuroscience Letters, 399, 245-248.

Campbell, L. E., Daly, E., Toal, F., Stevens, A., Azuma, R., Catani, M., ... Murphy, K. C. (2006). Brain and behaviour in children with 22q11.2 deletion syndrome: A volumetric and voxel-based morphometry MRI study. Brain, 129, 1218-1228.

Chow, E. W. C., Mikulis, D. J., Zipursky, R. B., Scutt, L. E., Weksberg, R., \& Bassett, A. S. (1999). Qualitative MRI findings in adults with 22q11 deletion syndrome and schizophrenia. Biological Psychiatry, 46, 1436-1442.

Cioffi, S., Martucciello, S., Fulcoli, F. G., Bilio, M., Ferrentino, R., Nusco, E., \& Illingworth, E. (2014). Tbx1 regulates brain vascularization. Human Molecular Genetics, 23, 78-89.

Cramer, S. C., Schaefer, P. W., \& Krishnamoorthy, K. S. (1996). Microgyria in the distribution of the middle cerebral artery in a patient with DiGeorge syndrome. Journal of Child Neurology, 11, 494-497.

DeBoer, T., Wu, Z., Lee, A., \& Simon, T. J. (2007). Hippocampal volume reduction in children with chromosome $22 q 11.2$ deletion syndrome is associated with cognitive impairment. Behavioral and Brain Functions, 3 , 54.

De Semdt, B., Devriendt, K., Fryns, J. P., Vogels, A., Gewillig, M., \& Swillen, A. (2007). Intellectual abilities in a large sample of children with velocardio-facial syndrome: An update. Journal of Intellectual Disability Research, 51(Pt 9), 666-670.

Edelmann, L., Pandita, R. K., \& Morrow, B. E. (1999). Low-copy repeats mediate the common 3-Mb deletion in patients with velo-cardio-facial Syndrome. American Journal of Human Genetics, 64, 1076-1086.

Eliez, S., Barnea-Goraly, N., Schmitt, J. E., Liu, Y., \& Reiss, A. L. (2002). Increased basal ganglia volumes in velo-cardio-facial syndrome (deletion 22q11.2). Biological Psychiatry, 52, 68-70.

Eliez, S., Schmitt, J. E., White, C. D., \& Reiss, A. L. (2000). Children and adolescents with velocardiofacial syndrome: A volumetric MRI study. American Journal of Psychiatry, 157, 409-415.

Emanuel, B. S. (2008). Molecular mechanisms and diagnosis of chromosome 22q11.2 rearrangements. Developmental Disabilities Research Reviews, 14, 11-18.

Fung, W. L., Butcher, N. J., Costain, G., Andrade, D. M., Boot, E., Chow, E. W., ... Bassett, A. S. (2015). Practical guidelines for managing adults with 22q11.2 deletion syndrome. Genetics in Medicine, 17(8), 599-609.

Ghariani, S., Dahan, K., Saint-Martin, C., Kadhim, H., Morsomme, F., Moniotte, S., ... Sébire, G. (2002). Polymicrogyria in chromosome 22q11 deletion syndrome. European Journal of Paediatric Neurology, 6 , 73-77.

Goodship, J., Cross, I., LiLing, J., \& Wren, C. (1998). A population study of chromosome 22q11 deletions in infancy. Archives of Disease in Childhood, 79, 348-351.
Guerrini, R., \& Carrozzo, R. (2001). Epileptogenic brain malformations: Clinical presentation, malformative patterns and indications for genetic testing. Seizure, 10(7), 532-543.

Hayashi, N., Tsutsumi, Y., \& Barkovich, A. (2002). Polymicrogyria without porencephaly/schizencephaly. MRI analysis of the spectrum and the prevalence of macroscopic findings in the clinical population. Neuroradiology, 44, 647-655.

Jalbrzikowski, M., Jonas, R., Senturk, D., Patel, A., Chow, C., Green, M. F., \& Bearden, C. E. (2013). Structural abnormalities in cortical volume, thickness, and surface area in 22q11.2 microdeletion syndrome: Relationship with psychotic symptoms. Neurolmage: Clinical, 3, 405-415.

Kates, W. R., Burnette, C. P., Bessette, B. A., Folley, B. S., Strunge, L., Jabs, E. W., \& Pearlson, G. D. (2004). Frontal and caudate alterations in velocardiofacial syndrome (deletion at chromosome 22q11.2). Journal of Child Neurology, 19, 337-342.

Kawame, H., Kurosawa, K., Akatsuka, A., Ochiai, Y., \& Mizuno, K. (2000). Polymicrogyria is an uncommon manifestation in 22q11.2 deletion syndrome. American Journal of Medical Genetics, 94, 77-78.

Kobrynski, L. J., \& Sullivan, K. E. (2007). Velocardiofacial syndrome, DiGeorge syndrome: The chromosome 22q11.2 deletion syndromes. Lancet, 370, 1443-1452.

Kraynack, N. C., Hostoffer, R. W., \& Robin, N. H. (1999). Agenesis of the corpus callosum associated with DiGeorge-velocardiofacial syndrome: A case report and review of the literature. Journal of Child Neurology, 14, 754-756.

Lynch, D. R., McDonald-McGinn, D. M., Zackai, E. H., Emanuel, B. S., Driscoll, D. A., Whitaker, L. A., \& Fischbeck, K. H. (1995). Cerebellar atrophy in a patient with velocardiofacial syndrome. Journal of Medical Genetics, 32, 561-563.

Maggadottir, S. M., \& Sullivan, K. E. (2013). The diverse clinical features of chromosome 22q11.2 deletion syndrome (DiGeorge syndrome). Journal of Allergy and Clinical Immunology, 1, 589-594.

McDonald-McGinn, D. M., \& Zackai, E. H. (2008). Genetic counseling for the 22q11.2 deletion. Developmental Disabilities Research Reviews, 14, 69-74.

McDonald-McGinn, D. M. M., \& Sullivan, K. E. (2011). Chromosome 22q11.2 deletion syndrome (DiGeorge syndrome/velocardiofacial syndrome). Medicine (Baltimore), 90, 1-18.

Mitnick, R. J., Bello, J. A., \& Shprintzen, R. J. (1994). Brain anomalies in velocardio-facial syndrome. American Journal of Medical Genetics, 54, 100-106.

Osborn, R. E., Mojtahedi, S., Hay, T. C., \& Dewitt, J. D. (1986). Internal carotid artery hypoplasia. Computerized Radiology, 10, 283-287.

Óskarsdóttir, S., Vujic, M., \& Fasth, A. (2004). Incidence and prevalence of the 22q11 deletion syndrome: A population-based study in Western Sweden. Archives of Disease in Childhood, 89, 148-151.

Rauch, A., Hoyer, J., Guth, S., Zweier, C., Kraus, C., Becker, C., ... Trautmann, U. (2006). Diagnostic yield of various genetic approaches in patients with unexplained developmental delay or mental retardation. American Journal of Medical Genetics Part A, 140A, 2063-2074.

Robin, N. H., \& Shprintzen, R. J. (2005). Defining the clinical spectrum of deletion 22q11.2. Journal of Pediatrics, 147, 90-96.

Robin, N. H., Taylor, C. J., McDonald-McGinn, D. M., Zackai, E. H., Bingham, P., Collins, K. J., ... Dobyns, W. B. (2006). Polymicrogyria and deletion 22q11.2 syndrome: Window to the etiology of a common cortical malformation. American Journal of Medical Genetics Part A, 140A, 2416-2425.

Ryan, A. K., Goodship, J. A., Wilson, D. I., Philip, N., Levy, A., Seidel, H., . . Scambler, P. J. (1997). Spectrum of clinical features associated with interstitial chromosome 22q11 deletions: A European collaborative study. Journal of Medical Genetics, 34, 798-804.

Schaer, M., Glaser, B., Cuadra, M. B., Debbane, M., Thiran, J.-P., \& Eliez, S. (2009). Congenital heart disease affects local gyrification in $22 q 11.2$ 
deletion syndrome. Developmental Medicine \& Child Neurology, 51, 746-753.

Schmitt, J. E., Yi, J. J., Roalf, D. R., Loevner, L. A., Ruparel, K., Whinna, D., . . Gur, R. E. (2014). Incidental radiologic findings in the 22q11.2 deletion syndrome. American Journal of Neuroradiology, 35(11), 2186-2191.

Shprintzen, R. J. (2008). Velo-cardio-facial syndrome: 30 years of study. Developmental Disabilities Research Reviews, 14, 3-10.

Simon, T. J., Ding, L., Bish, J. P., McDonald-McGinn, D. M., Zackai, E. H., \& Gee, J. (2005). Volumetric, connective, and morphologic changes in the brains of children with chromosome 22q11.2 deletion syndrome: An integrative study. Neuroimage, 25, 169-180.

Sprecher, E., Ishida-Yamamoto, A., Mizrahi-Koren, M., Rapaport, D., Goldsher, D., Indelman, M., ... Mandel, H. (2005). A mutation in SNAP29, coding for a SNARE protein involved in intracellular trafficking, causes a novel neurocutaneous syndrome characterized by cerebral dysgenesis, neuropathy, ichthyosis, and palmoplantar keratoderma. American Journal of Human Genetics, 77, 242-251.

Swillen, A., \& McDonald-McGinn, D. (2015). Developmental trajectories in 22q11.2 deletion. American Journal of Medical Genetics Part C, $169 \mathrm{C}(2), 172-181$.
Tezenas Du Montcel, S., Mendizabai, H., Ayme, S., Levy, A., \& Philip, N. (1996). Prevalence of 22q11 microdeletion. Journal of Medical Genetics, 33, 719.

Van Amelsvoort, T., Daly, E., Robertson, D., Suckling, J., Ng, V., Critchley, H., ... Murphy, D. G. M. (2001). Structural brain abnormalities associated with deletion at chromosome 22q11: Quantitative neuroimaging study of adults with velo-cardio-facial syndrome. British Journal of Psychiatry, 178, 412-419.

Vitelli, F., Viola, A., Morishima, M., Pramparo, T., Baldini, A., \& Lindsay, E. (2003). TBX1 is required for inner ear morphogenesis. Human Molecular Genetics, 12, 2041-2048.

How to cite this article: Bohm LA, Zhou TC, Mingo TJ, et al. Neuroradiographic findings in 22q11.2 deletion syndrome. Am J Med Genet Part A. 2017;173A:2158-2165. https://doi.org/10.1002/ajmg.a.38304 